\title{
Cluster randomized controlled trial of a mobile market intervention to increase fruit and vegetable intake among adults in lower-income communities in North Carolina
}

Lucia A. Leone ${ }^{1 *}$ (D), Gina L. Tripicchio², Lindsey Haynes-Maslow ${ }^{3}$, Jared McGuirt ${ }^{2}$, Jacqueline S. Grady Smith², Janelle Armstrong-Brown ${ }^{4}$, Ziya Gizlice ${ }^{2}$ and Alice Ammerman ${ }^{2}$

\begin{abstract}
Background: Poorer diets and subsequent higher rates of chronic disease among lower-income individuals may be partially attributed to reduced access to fresh fruits and vegetables (F\&V and other healthy foods. Mobile markets are an increasingly popular method for providing access to F\&V in underserved communities, but evaluation efforts are limited. The purpose of this study was to determine the impact of Veggie Van (W), a mobile produce market, on F\&V intake in lower-income communities using a group randomized controlled trial.

Methods: $W$ is a mobile produce market that sells reduced-cost locally grown produce and offers nutrition and cooking education. We recruited 12 sites in lower-income communities in North Carolina (USA) to host W, randomizing them to receive $\mathrm{W}$ immediately (intervention) or after the 6-month study period (delayed intervention control). Participants at each site completed baseline and follow-up surveys including F\&V intake, perceived access to fresh F\&V and self-efficacy for purchasing, preparing and eating F\&V. We used multiple linear regression to calculate adjusted differences in outcomes while controlling for baseline values, education and clustering within site.

Results: Among 142 participants who completed the follow-up, baseline F\&V intake was 3.48 cups/day for control and 3.33 for intervention. At follow-up, adjusted change in F\&V consumption was 0.95 cups/day greater for intervention participants $(p=0.005)$, but was attenuated to 0.51 cups per day $(p=0.11)$ after removing extreme values. W customers increased their F\&V consumption by 0.41 cups/day $(n=30)$ compared to a 0.25 cups/day decrease for 111 non-customers $(p=0.04)$. Intervention participants did not show significant improvements in perceived access to fresh $F \& V$, but increased their self-efficacy for working more F\&V into snacks $(p=0.02)$, making up a vegetable dish with what they had on hand $(p=0.03)$, and cooking vegetables in a way that is appealing to their family $(p=0.048)$.
\end{abstract}

Conclusions: Mobile markets may help improve F\&V intake in lower-income communities.

Trial registration: Clinicaltrials.gov ID\# NCT03026608 retrospectively registered January 2, 2017.

Keywords: Food environment, Mobile market, Lower-income, Cluster-randomized trial, Fruits and vegetables

\footnotetext{
*Correspondence: lucialeo@buffalo.edu

${ }^{1}$ Department of Community Health and Health Behavior, University at

Buffalo, Buffalo, NY, USA

Full list of author information is available at the end of the article
} 


\section{Background}

In the United States, lower-income Americans have higher rates of chronic disease than those with higher income and are also more likely to have poor diets [1]. Adults who consume fewer foods high in saturated fat, sodium and sugar in favor of fruits and vegetables $(\mathrm{F} \& \mathrm{~V})$ are less likely to develop heart disease, type 2 diabetes, certain types of cancer, and are more likely to sustain a healthy weight [2]. While the benefits of consuming F\&V are recognized by many [3], low-income individuals are often unable to purchase as much F\&V as they would like due to multiple factors including limited access to high quality, fresh and/or affordable F\&V $[4,5]$. Thus, strategies to improve access for this population are needed.

While many experts believe that providing more options for purchasing fresh produce in underserved communities could help improve consumption of F\&V [6], the research supporting this strategy is limited. Several initiatives have been directed at improving access to fresh produce; for example, the Healthy Food Financing Initiative provides financial incentives for supermarkets to open in communities that have limited food retail options [7]. Despite these efforts, none of the studies examining the effects of new grocery stores have shown an impact on F\&V consumption [8-10], although they have shown other benefits regarding improved perceptions of neighborhoods [9]. One challenge faced by larger retail outlets is that in addition to selling fresh produce, they also offer many unhealthy options. Additionally, produce marketed in lower-income communities is sometimes poorer in quality and higher in price [4].

Given the challenges with opening new grocery stores in lower-income areas (e.g., high start-up costs, zoning ordinances, perceived lack of customer demand or buying power), there is a need for alternative food sources; Farmer's markets, Community-Supported Agriculture (CSA; i.e., commitment to a farm to purchase a share of their produce for a set period of time), and mobile markets generally focus exclusively or predominately on F\&V and provide fresh (often locally grown), affordable produce. While these strategies are promising [11-16], there are few studies examining their efficacy and at the time of this study there were no randomized controlled trials. Experts have noted the need for stronger study designs to better understand the relationship between the food environment and diet, and identify scalable solutions [6]. Our study sought to fill this gap by rigorously evaluating the impact of a mobile produce market program on $\mathrm{F} \& \mathrm{~V}$ consumption among individuals in lower-income communities in North Carolina.

We conducted a cluster randomized controlled trial to evaluate the impact of Veggie Van (VV), a mobile produce market, on $\mathrm{F} \& \mathrm{~V}$ intake of participants living in lower-income communities in NC. This paper reports the effect of 6-months of exposure to the VV program on diet, perceived access to fresh F\&V and self-efficacy. We compare effects between intervention and control communities and examine the relationship between $\mathrm{VV}$ purchasing and changes in diet.

\section{Methods}

The Green Cart Evaluation Study was an evaluation of the VV program conducted between 2012 and 2015 in four counties in North Carolina. For the evaluation, we randomized 12 potential $\mathrm{VV}$ sites to receive the $\mathrm{VV}$ program immediately after baseline data collection (intervention) or after a 6-month waitlist period (delayed intervention control). This study was retrospectively registered with Clinicaltrials.gov (ID\# NCT03026608) on January 2, 2017.

\section{Veggie van program}

The VV was a mobile produce market, run by the nonprofit organization Community Nutrition Partnership, that offered high-quality produce aggregated from multiple local farms to customers at a reduced price [15]. The socioecological model acts as a guiding framework for addressing the complexities associated with dietary intake in high-need populations. The socioecological model posits that multiple levels of influences (e.g., individual, interpersonal, and community-level factors) intersect to yield outcomes [17]. Social Cognitive Theory provides constructs that support the goal of targeting behavior change on at the individual and environmental levels. Specifically, VV sought to change the food environment (and people's perceptions of it) while simultaneously improving selfefficacy to purchase, prepare and eat fresh F\&V.

Aspects of the food environment addressed by VV included availability, accessibility, acceptability, affordability, and accommodation [18]. VV increased the number of food outlets within target communities by partnering with local community organizations that were already frequented by or in locations near the target population (accessibility) and selling produce at those locations (availability). Locations included health clinics, recreation centers, libraries, housing communities and community centers $[15,19]$. The VV mobile market was held weekly during the 6-month intervention period, unless staffing or weather issues prevented the market from operating. Customers could pay week-to-week for shares of produce (i.e., similar to a CSA they would receive a set amount of seasonally available produce items offered at the same price each week) or buy individual produce items at the market. In order to ensure VV offered high quality produce, all the F\&V were fresh, locally grown, and often organic (acceptability). Produce was offered at about half the cost of traditional CSA programs (affordability). Unlike CSA programs, no upfront payments or 
commitments were required though pre-ordering was encouraged and incentivized with monetary discounts. To maximize accommodation, VV accepted multiple forms of payment (cash, credit/debit, check and the Supplemental Nutrition Assistance Program's (SNAP) electronic benefit transfer (EBT) cards) and visited sites at times which were assessed to be the most convenient for potential customers.

The educational intervention addressed individual skills and behaviors related to F\&V consumption with the goal of improving self-efficacy through increased outcome expectations/expectancies, observational learning and behavioral capability. Newsletters and nutrition demonstrations addressed the benefits of healthy eating (expectations). Social marketing campaigns at VV sites encouraged people to come to markets to benefit from VV (expectancies). VV also provided cooking demonstrations, tips for cooking seasonal produce and recipes for items sold at VV (behavioral capability and observational learning). While outside the context of research, customers only received weekly newsletters when they visited the $\mathrm{VV}$, for the purposes of this evaluation, research participants at intervention sites received newsletters by mail or e-mail even if they did not visit VV. Since we could not require study participants to shop at $\mathrm{VV}$, we sent them the newsletters as a way of ensuring that they were aware of the program and at least received some dose of the behavioral intervention.

\section{Recruitment}

The Green Cart study and VV teams partnered with organizations that were serving the priority population (lower-income and/or limited access to fresh produce) to facilitate the research. Site and participant recruitment are described in detail elsewhere $[19,20]$. We asked partner organizations to collect at least 30 interest forms from community members who were potentially interested in purchasing VV produce and who were willing to participate in a research study. A member of the research team contacted those who completed the forms and asked them to participate in a study. Eligible individuals (Age 18 or older, English speaking, and primary food shopper for their household) were invited to complete a telephone-administered baseline survey and were enrolled in the study. After participant data collection was completed, we randomized sites in pairs to either the intervention or the delayed intervention control group. Institutional Review Board at the university approved all procedures.

\section{Survey and measures}

We collected all data over the phone via intervieweradministered surveys at baseline and 6-months. Additional details on data collection and measures can be found elsewhere [20].

\section{Dietary outcomes}

The primary outcome, F\&V intake (cups/day), was assessed using the 10-item National Cancer Institute F\&V screener and calculated according to the screener instructions [21]. A validation study found estimated correlations between the screener and F\&V intake from 4 non-consecutive 24-h recalls were 0.67 for men and 0.53 for women [22]. Testretest reliability for similar food frequency questionnaires (FFQs) is generally good (ICC $=0.65)$ [23]. Added sugar (servings/day) was calculated from the 7-items selected from the National Health and Nutrition Examination Survey Dietary Screener to capture consumption in the past month including sugar-sweetened beverages, chocolate or candy, pastries, desserts or ice cream [24].

\section{Psychosocial measures}

In order to measure the impact of the environmentallevel intervention components, we assessed participant's perceived access to fresh $F \& V$ assessed using a 3-item scale $[25,26]$ adapted to examine access using three different definitions: one assessing perceived neighborhood access, one assessing perceived access near the VV location in their community, and one assessing general perceived access. Possible perceived access scores range from 3 (strongly disagree to all items) to 15 (strongly agree to all items), with a midpoint of 8 indicating a neutral response. The impact of the nutrition education intervention component was assessed by looking at selfefficacy to purchase, prepare and eat F\&V. Self-efficacy was assessed using nine questions (shown in Table 4) with response options ranging from 1 to $10(1=$ "very easy" to $10=$ "very hard") [27]. Items were summed to create a total self-efficacy score (range 9 to 90 ).

\section{VV usage and implementation measures}

On the survey, participants were asked to report if they had ever used VV; we also reviewed sales data to see if participants made any purchases at VV during the intervention period. If a participant purchased at least one share of produce, they were recorded as a customer. Participants who only purchased individual produce items were not identified by name and not included in the sales data. In order to understand VV program implementation and fidelity, coordinators were asked to fill out a process measures form after each market. Process data will be reported separately.

\section{Power analysis}

Our original power analysis was based on F\&V servings/ day as calculated by the National Cancer Institute F\&V screener. In the sample size estimates, we considered correlated change in F\&V intake among participants within a community site (ICC), number of participants within each site and number of sites (clusters) [28, 29]. 
The VV program was expected to increase the F\&V consumption by least 1.25 servings per day or approximately 0.75 cups/day (effect size of approximately 0.35 ) based on the VV pilot [15]. A sample size of 6 communities per group with 20 participants in each community yielded 0.80 power to detect 0.75 cup difference in mean changes between two groups using two-sided tests of significance at $p=0.05$, assuming an ICC of 0.001 and standard deviation of 3.6 based on other cluster randomized trials [30]. We assumed attrition to be no more than $20 \%$ based on the pilot study [15]. Thus, a final goal was to recruit at least 25 participants in each community, for a total of 300 participants.

\section{Analysis}

A generalized linear mixed model (GLMM) with a random intercept to control for clustering within community sites was used to test the effect of the VV intervention on dietary intake (F\&V and added sugar) at 6-months. Additional GLMM variables included: 1) baseline diet as fixed covariate, and 2) baseline diet and education. Including the baseline values as a covariate, in an analysis of covariance (ANCOVA) is known to be a more powerful test than a group comparison of baseline to post-intervention change (26). ANCOVA is not distorted by regression towards the mean bias, whereas a change analysis is subject to that bias [31, 32]. We controlled for education because both income and education were significantly higher among control participants at baseline. These items were highly correlated and education was more consistently reported than income. Additionally, we completed a sensitivity analysis on the final model excluding extreme $F \& V$ reporters. Extreme F\&V reporters were defined as participants who had a change greater than 9-cups of F\&V per day. All secondary outcome analyses were conducted using GLMMs (e.g., usage, perceived access, self-efficacy), removed extreme reporters (when $F \& V$ intake was the outcome) and controlled for baseline values, education and clustering within sites.

\section{Results}

Interest forms were collected from 516 individuals across 12 sites. A total of 201 participants enrolled into the study and completed baseline measures: 113 intervention and 88 control. Site-by-site recruitment ranged from $23.5 \%$ to $50 \%$ (see Additional file 1). A total of 142 participants completed the 6-month follow-up survey: 74 intervention and 68 control; this represented a $70.6 \%$ retention rate. Site-by-site retention ranged from $39.1 \%$ to $90 \%$ (see Additional file 1). Study participant drop-out was predominately due to the research team not being able to contact the participant (e.g., participant was non-responsive after 6 or more attempts, number was disconnected, and alternate contact attempts were not successful) (Fig. 1). There were no differences between study completers and drop-outs in regards to any of the demographic data or F\&V consumption at baseline.

\section{Demographics}

Baseline characteristics for 142 study completers, by treatment arm, are summarized in Table 1. Overall, the sample was predominately female (95.8\%), African American (64.8\%), and not married (66.7\%). On average, the sample was $46.3 \pm 14.0$ years old, obese (mean BMI $=31.3 \pm 7.8$ ), and had two adults and two children living in the household. More than half (54.0\%) made less than $\$ 30,000$ per year and $62.0 \%$ received some form of government assistance (i.e., SNAP, Medicaid).

\section{Dietary intake}

\section{Intervention vs. control}

Dietary intake data are shown in Table 2. F\&V intake at baseline was 3.33 (SD 2.36) cups/day for the intervention group and 3.48 (SD 3.14) cups/day for the control group. At follow-up, intervention participants increased their intake by 0.31 cups/day and control participants decreased their intake by 0.66 cups/day. Intervention participants had significantly higher F\&V intake than control participants at follow-up $(p=0.05)$. The difference in mean changes after adjusting for clustering, baseline intake and education was 0.95 cups per day $(p=0.005)$. We conducted a sensitivity analysis removing four participants who had extreme F\&V changes and found that the difference was attenuated to $0.51 \mathrm{cups} /$ day $(p=0.11)$. The intraclass correlation (ICC) for change in F\&V intake by site was 0.08 .

Sugar intake at baseline was 2.31 (SD 2.23) servings/ day for the intervention group and 1.84 (SD 1.45) servings/day for the control group. Both groups decreased their sugar intake at follow-up, but there were no significant changes in added sugar intake between the intervention and control groups at 6-month follow-up in any of the models.

\section{F\&V intake by veggie van usage}

At 6-month follow-up, almost all intervention participants reported being aware of the $\mathrm{VV}$ at their site $(n=71,95.5 \%)$. Of those, 47 intervention participants self-reported ever purchasing from VV (63.5\%). Additionally, 2 control participants also reported shopping at $\mathrm{VV}$ during the initial 6-month period. We compared change in F\&V intake for those who reported ever purchasing from VV (+0.07 cups, $n=47$ after two removing extreme $F \& V$ reporters) versus those who did not report shopping at VV $(-0.26$ cups/day, $n=85)$ and did not find any statistically significant differences $(p=$ 0.32 ). However, VV sales data indicated that participants who had at least one share purchase on record 


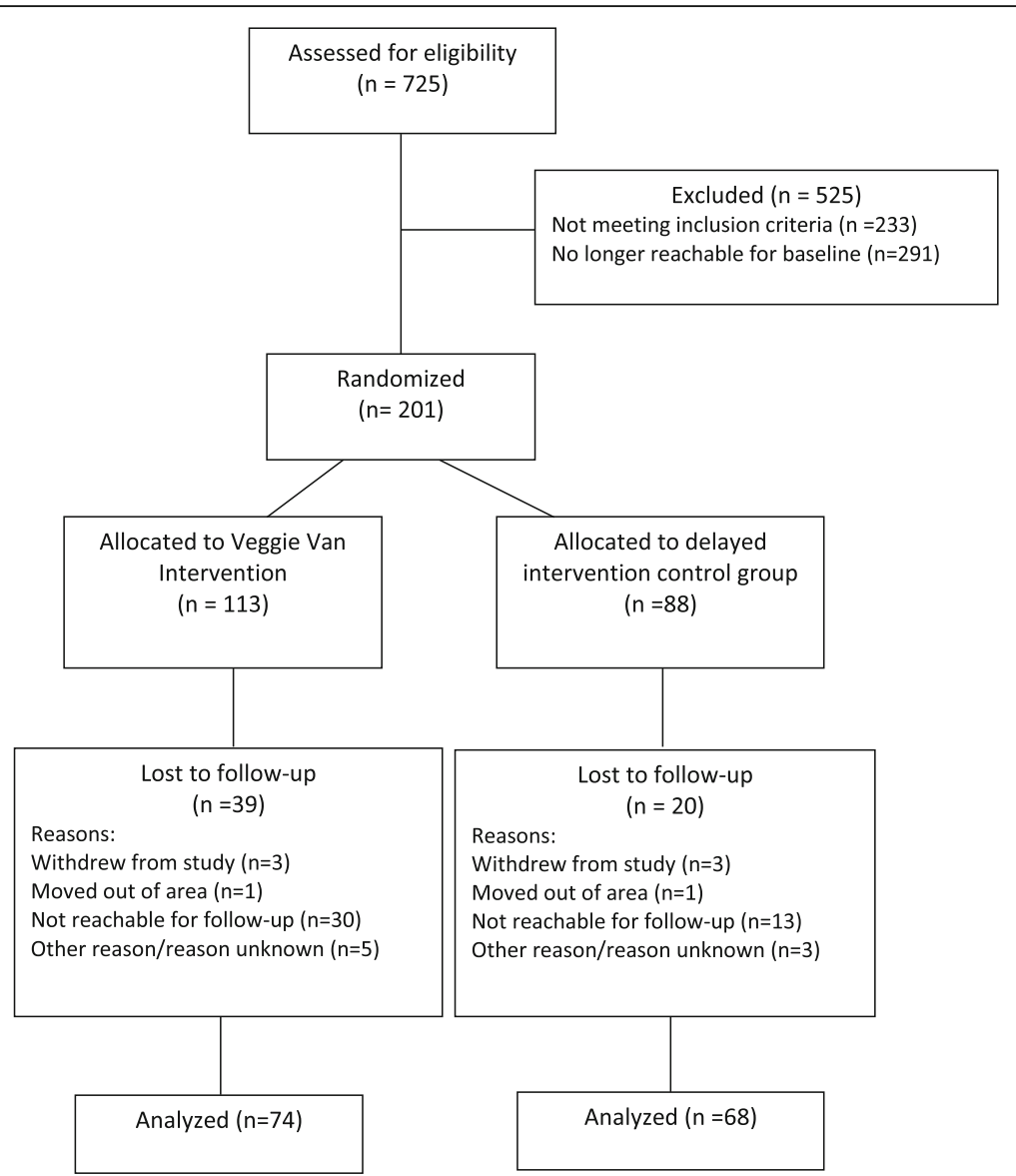

Fig. 1 Recruitment and randomization of participants for the Veggie Van mobile market program and the Green Cart Evaluation study

during the intervention period reported greater adjusted changes ( 0.41 cups/day, $n=30)$ in F\&V consumption at 6months than those who had no purchasing record $(-0.25$ cups/day, $n=111)$; this represented a 0.67 cup/ day difference overall between groups $(p=0.04)$. There was also some evidence of dose-response among those who used VV; after adjusting for co-variates intervention participants who reported purchasing from VV three or four times over the past month $(n=8)$ had a $1.14 /$ cup per day greater change in F\&V intake compared to those who reported 1 or 2 purchases over the past month $(n=23):+0.47$ cups/day vs. -0.67 cups/day $(p=0.04)$.

\section{Perceived access}

Perceived access to fresh F\&V is reported in Table 3. There were no statistically significant changes in neighborhood perceived access, perceived access near the VV site, or general perceived access at 6-months. We also did not observe any changes in participants reporting that they could afford enough F\&V to feed their families.

\section{Self-efficacy}

Self-efficacy at 6-months is reported in Table 4. While total self-efficacy at follow-up was slightly higher for the intervention group (61.5) vs. the control group (57.4), this difference was not statistically significant $(p=0.10)$. Intervention participants did have greater improvements in self-efficacy compared to control for three scale items: working more $\mathrm{F} \& \mathrm{~V}$ into snacks $(1.23, p=0.02)$, making up a vegetable dish with what they had on hand (0.94, $p=0.03)$, and cooking vegetables in a way that is appealing to their family $(0.89, p=0.048)$.

\section{Discussion}

Our findings suggest that participants at sites that received the VV improved their F\&V consumption as compared to participants at sites assigned to the control condition, however much of the difference we saw was due to a decrease in the control group and findings were attenuated after extreme values were removed. Our original hypothesis for this research was that in order to accommodate an increase in F\&V intake, participants would need to decrease something else in their diet. We expected to see a decrease in sugar as a result, but our data did not confirm this hypothesis. 
Table 1 Baseline characteristics of Veggie Van study Participants by intervention condition

\begin{tabular}{|c|c|c|c|}
\hline Variable & Entire Sample & Intervention & Control \\
\hline \multicolumn{4}{|l|}{ Gender, \% } \\
\hline Male & $4.2 \%$ & $6.8 \%$ & $1.5 \%$ \\
\hline Female & $95.8 \%$ & $93.2 \%$ & $98.5 \%$ \\
\hline Age, mean (SD) & $46.30(14.01)$ & 47.89 (14.89) & $44.52(12.83)$ \\
\hline $\begin{array}{l}\text { Number of Adults in } \\
\text { Household, mean (SD) }\end{array}$ & $1.96(1.17)$ & $1.99(1.45)$ & $1.93(0.78)$ \\
\hline $\begin{array}{l}\text { Number of Children in } \\
\text { Household, mean (SD) }\end{array}$ & $2.17(1.24)$ & $2.22(1.40)$ & $2.12(1.04)$ \\
\hline Hispanic/Latino, \% & $2.1 \%$ & $2.7 \%$ & $1.5 \%$ \\
\hline \multicolumn{4}{|l|}{ Race, \% } \\
\hline Black/African American & $64.8 \%$ & $68.1 \%$ & $64.2 \%$ \\
\hline White & $31.0 \%$ & $29.2 \%$ & $34.3 \%$ \\
\hline American Indian & $0.7 \%$ & $1.4 \%$ & $0 \%$ \\
\hline Other & $1.4 \%$ & $1.4 \%$ & $1.5 \%$ \\
\hline \multicolumn{4}{|l|}{ Marital Status, \% } \\
\hline Married & $33.3 \%$ & $30.1 \%$ & $36.8 \%$ \\
\hline Never Married & $46.8 \%$ & $47.9 \%$ & $45.6 \%$ \\
\hline $\begin{array}{l}\text { Divorced/Separated/ } \\
\text { Widowed }\end{array}$ & $19.9 \%$ & $21.9 \%$ & $17.6 \%$ \\
\hline \multicolumn{4}{|l|}{ Education, \% } \\
\hline $\begin{array}{l}\text { High School Grad or less, } \\
\text { GED, Trade or Beauty School }\end{array}$ & $32.9 \%$ & $37.8 \%$ & $27.3 \%$ \\
\hline Some College & $26.4 \%$ & $25.7 \%$ & $54.5 \%$ \\
\hline College Graduate & $20.7 \%$ & $17.6 \%$ & $24.2 \%$ \\
\hline More than college & $20.0 \%$ & $18.9 \%$ & $21.2 \%$ \\
\hline \multicolumn{4}{|l|}{ Income, \% } \\
\hline$<10,000$ & $21.8 \%$ & $28.6 \%$ & $14.8 \%$ \\
\hline $10,000-29,999$ & $32.2 \%$ & $34.9 \%$ & $29.6 \%$ \\
\hline $30,000-49,999$ & $21.0 \%$ & $14.2 \%$ & $27.9 \%$ \\
\hline 50,000 or more & $25.0 \%$ & $22.2 \%$ & $27.9 \%$ \\
\hline BMI, mean (SD) & $31.29(7.81)$ & $31.14(7.85)$ & $31.46(7.82)$ \\
\hline \multicolumn{4}{|c|}{ Receiving Government Assistance, \% } \\
\hline SNAP & $33.8 \%$ & $29.7 \%$ & $38.2 \%$ \\
\hline WIC & $19.0 \%$ & $16.2 \%$ & $22.1 \%$ \\
\hline Free/reduced price lunch & $30.3 \%$ & $31.1 \%$ & $29.4 \%$ \\
\hline Medicaid & $43.7 \%$ & $48.6 \%$ & $38.2 \%$ \\
\hline TANF & $3.5 \%$ & $5.4 \%$ & $1.5 \%$ \\
\hline None & $38.0 \%$ & $35.1 \%$ & $41.2 \%$ \\
\hline
\end{tabular}

$N=142$ (Intervention $n=74$; Control $n=68$ ) for measures of gender, number of adults in the household, number of children in the household, Hispanic/Latino; $N=140$ (Intervention $n=74$; Control $n=66$ ) for age and education; $N=139$ (Intervention $n=72$; Control $n=67$ ) for race; $N=141$ (Intervention $n=73$; Control $n=67$ ) for marital status; $N=124$ (Intervention $n=63$; Control $n=61$ ) for income; $N=131$ (Intervention $n=70$; Control $n=61$ ) for BMI

$S D$ standard deviation, GED general educational development proficiency, BMI body mass index, SNAP supplemental nutrition assistance program, WIC Special Supplemental Nutrition Program for Women, Infants and Children, TANF Temporary Assistance for Needy Families
While this is the first published report of a randomized controlled trial for a mobile market, main outcomes findings are consistent with other pre-post design mobile market studies that generally show an increase in F\&V consumption of about 1 cup ( 2 servings) per day [12-14]. Sub-group analyses looking at F\&V consumption among VV shoppers vs. those who did not use VV were similar to previous pilot work that showed a 1.6/ serving per day (approx. $0.8 \mathrm{cup} /$ day) improvement for customers compared to non-customers [15]. For the main outcomes analysis, we would expect changes in intake for the current study to be attenuated in comparison to previous studies. Previous research has only looked at changes in intake for those who received the intervention whereas we used an intent-to-treat design and there was no guarantee that the participants recruited for this study would shop at VV. We found that exposure to the environmental intervention was limited; while a majority of intervention participants reported using VV, purchases reported in the past month (when it would likely affect F\&V intake at follow-up) were limited. Future studies should consider additional outreach strategies and study designs to ensure that more participants become and remain customers for the duration of the intervention in order to better estimate efficacy. For example, baseline data could be collected at the time of first purchase and subscriptions could encourage continued use. In addition, better sales data are needed to understand dose response; our data were only able to indicate if customers ever purchased a share, but could not track individual produce purchases.

To further understand our findings, we looked at two scales which were meant to measure the effect of two aspects of this intervention as described in our conceptual model [20]. A perceived access scale was designed to capture the environmental aspects of the intervention (improvements in availability, quality, and affordability of fresh produce) and a self-efficacy scale was used to assess behavioral aspects of the intervention (behavioral capability for purchasing, preparing and eating fresh F\&V). Perceived access was already high at baseline and while there were small increases in the intervention group, none were statistically significant. This may also be due to the fact that only about $2 / 3$ of participants actually shopped at the VV so not everyone received the full intervention dosage. While nearly everyone in the intervention group was aware of $\mathrm{VV}$, this may not have been enough to increase their perceived access. Thus, we would hypothesize, based on the conceptual model, that the changes we saw in F\&V consumption may be partially mediated by changes in self-efficacy due to the behavioral intervention.

Greater F\&V consumption for the intervention group and VV users may also be the result of aspects of our 
Table 2 Changes in dietary intake among Veggie Van study completers by intervention condition

\begin{tabular}{|c|c|c|c|c|}
\hline \multicolumn{5}{|l|}{ F\&V Intake (Cups/Day) } \\
\hline Outcome & $\begin{array}{l}\text { Intervention }(n=74) \\
\text { Meant (SE) }\end{array}$ & $\begin{array}{l}\text { Control }(n=68) \\
\text { Meant }(S E)\end{array}$ & $\begin{array}{l}\text { Intervention Effect } \\
\text { Mean Differencet (SE) }\end{array}$ & $P$-valuet \\
\hline Baseline & $3.33(0.27)$ & $3.48(0.38)$ & $-0.15(0.46)$ & 0.75 \\
\hline 6-month Follow-up & $3.64(0.30)$ & $2.82(0.19)$ & $0.81(0.36)$ & $0.05^{*}$ \\
\hline \multicolumn{5}{|c|}{ Change at 6-months controlling for clustering } \\
\hline & $0.41(0.46)$ & $-0.64(0.46)$ & $01.06(0.65)$ & 0.14 \\
\hline \multicolumn{5}{|c|}{ Change at 6-months controlling for clustering and baseline F\&V intake } \\
\hline & $0.34(0.31)$ & $-0.59(0.32)$ & $0.93(0.45)$ & 0.06 \\
\hline \multicolumn{5}{|c|}{ Change at 6-months controlling for clustering, baseline F\&V intake, and education } \\
\hline & $0.30(0.28)$ & $-0.65(0.09)$ & $0.95(0.30)$ & $0.005^{*}$ \\
\hline \multicolumn{5}{|c|}{ Change at 6-months controlling for clustering, baseline F\&V intake, and education (extremes removed) } \\
\hline & $0.14(0.20)$ & $-0.37(0.20)$ & $0.51(0.28)$ & 0.11 \\
\hline \multicolumn{5}{|c|}{ Added Sugar Intake (Servings/Day) } \\
\hline Outcome & $\begin{array}{l}\text { Intervention } \\
\text { Meant (SE) }\end{array}$ & $\begin{array}{l}\text { Control } \\
\text { Meant (SE) }\end{array}$ & $\begin{array}{l}\text { Intervention Effect } \\
\text { Mean Differencet (SE) }\end{array}$ & $p$-value \\
\hline Baseline & $2.31(0.26)$ & $1.84(0.18)$ & $0.47(0.31)$ & 0.14 \\
\hline 6-month Follow-up & $2.19(0.23)$ & $1.71(0.16)$ & $0.48(0.32)$ & 0.10 \\
\hline \multicolumn{5}{|c|}{ Change at 6-months controlling for clustering } \\
\hline & $-0.15(0.27)$ & $-0.13(0.27)$ & $0.02(0.38)$ & 0.96 \\
\hline \multicolumn{5}{|c|}{ Change at 6-months controlling for clustering and baseline sugar intake } \\
\hline & $-.07(0.23)$ & $-.26(0.23)$ & $0.19(0.32)$ & 0.51 \\
\hline \multicolumn{5}{|c|}{ Change at 6-months controlling for clustering, baseline sugar intake, and education } \\
\hline & $-.07(0.23)$ & $-.26(0.23)$ & $0.19(0.32)$ & 0.52 \\
\hline
\end{tabular}

†All means, mean differences and $p$-values are adjusted for clustering within sites and any other controls specified within the model; *statistically significant $(p<0.05)$

F\&V fruit and vegetables, SD Standard Deviation, SE Standard Error

Table 3 Change in perceived access to fresh fruits and vegetables for study completers by intervention condition

\begin{tabular}{|c|c|c|c|}
\hline Perceived Access Scale & Intervention & Control & $\begin{array}{l}\text { Intervention Effect } \\
\text { Adjusted Mean Difference } \\
\text { (SE), p-value }\end{array}$ \\
\hline \multicolumn{4}{|l|}{ General (3-item) } \\
\hline Baseline, mean (SD) & $11.12(3.11)$ & $10.72(2.65)$ & $-0.23(0.37)$ \\
\hline Adjusted Change ${ }^{a}$, mean (SE) & $0.74(0.27)$ & $0.97(0.27)$ & $p=0.54$ \\
\hline \multicolumn{4}{|l|}{ Veggie Van Site (3-item) } \\
\hline Baseline, mean (SD) & $8.10(3.40)$ & $8.34(2.96)$ & $0.46(0.69)$ \\
\hline Adjusted Change ${ }^{a}$, mean (SE) & $1.57(0.49)$ & $1.10(0.49)$ & $p=0.52$ \\
\hline \multicolumn{4}{|l|}{ Home (3-item) } \\
\hline Baseline, mean (SD) & $10.38(3.33)$ & $9.93(3.28)$ & $-0.38(0.64)$ \\
\hline Adjusted Change ${ }^{a}$, mean (SE) & $0.26(0.45)$ & $0.64(0.46)$ & $p=0.57$ \\
\hline \multicolumn{4}{|l|}{ Afford F\&V (1-item) } \\
\hline Baseline, mean (SD) & $3.46(1.21)$ & $3.24(1.22)$ & $0.07(0.17)$ \\
\hline Adjusted Change ${ }^{a}$, mean (SE) & $0.23(0.12)$ & $0.16(0.12)$ & $p=0.67$ \\
\hline
\end{tabular}

analysis adjusted for site, baseline perceived access and education

$\mathrm{N}=142$ for general scale and Afford F\&V (intervention =74, control=68); $N=131$ for Veggie Van Site scale (intervention = 167, control =64); $N=139$ for home scale (intervention $=72$, control $=67$ )

F\&V Fruits and Vegetables, SD Standard Deviation, SE Standard Error 
Table 4 Change in self-efficacy for purchasing, eating and preparing fruits and vegetables by intervention condition

\begin{tabular}{|c|c|c|c|c|}
\hline Self-Efficacy Item & & $\begin{array}{l}\text { Intervention } \\
(n=64)\end{array}$ & $\begin{array}{l}\text { Control } \\
(n=64)\end{array}$ & $\begin{array}{l}\text { Intervention Effect } \\
\text { Adjusted Mean } \\
\text { Differencet (SE), p-value }\end{array}$ \\
\hline \multirow{2}{*}{$\begin{array}{l}\text { 1. How easy or hard would it be for you to buy more fruits } \\
\text { and vegetables than you normally do the next time you shop? }\end{array}$} & Baseline, mean (SD) & $6.74(3.24)$ & $6.90(3.01)$ & $0.31(0.44)$ \\
\hline & Adjusted Changet, mean (SE) & $0.71(0.31)$ & $0.40(0.32)$ & $p=0.49$ \\
\hline \multirow{2}{*}{$\begin{array}{l}\text { 2. How easy or hard would it be for you to use all of the fruits } \\
\text { and vegetables that you buy before they go bad? }\end{array}$} & Baseline, mean (SD) & $7.35(2.73)$ & $6.83(2.71)$ & $-0.01(0.40)$ \\
\hline & Adjusted Changet, mean (SE) & $0.46(0.29)$ & $0.47(0.29)$ & $p=0.98$ \\
\hline \multirow{2}{*}{$\begin{array}{l}\text { 3. How easy or hard would it be for you to work more fruits } \\
\text { and vegetables than you normally do into meals for yourself } \\
\text { and your family? }\end{array}$} & Baseline, mean (SD) & $7.26(2.72)$ & $7.29(2.60)$ & $0.54(0.42)$ \\
\hline & Adjusted Changet, mean (SE) & $0.46(0.30)$ & $-0.08(0.30)$ & $P=0.21$ \\
\hline \multirow{2}{*}{$\begin{array}{l}\text { 4. How easy or hard would it be for you to work more fruits } \\
\text { and vegetables than you normally into snacks for yourself } \\
\text { and your family? }\end{array}$} & Baseline, mean (SD) & $7.04(3.05)$ & $7.09(2.71)$ & $1.23(0.53)$ \\
\hline & Adjusted Changet, mean (SE) & $1.10(0.38)$ & $-0.13(0.38)$ & $p=0.02^{*}$ \\
\hline \multirow{2}{*}{$\begin{array}{l}\text { 5. How easy or hard would it be for you to cook vegetables in a } \\
\text { way that is appealing to your family? }\end{array}$} & Baseline, mean (SD) & $7.27(2.98)$ & $7.67(2.48)$ & $0.94(0.42)$ \\
\hline & Adjusted Changet, mean (SE) & $0.89(0.30)$ & $-0.06(0.30)$ & $p=0.03^{*}$ \\
\hline \multirow{2}{*}{$\begin{array}{l}\text { 6. How easy or hard would it be for you to make-up a vegetables } \\
\text { dish with what you have on hand? }\end{array}$} & Baseline, mean (SD) & $7.55(2.74)$ & $6.99(2.77)$ & $0.90(0.45)$ \\
\hline & Adjusted Changet, mean (SE) & $0.80(0.32)$ & $-0.10(0.33)$ & $p=0.048^{*}$ \\
\hline \multirow{2}{*}{$\begin{array}{l}\text { 7. How easy or hard would it be for you to try vegetables that } \\
\text { you have not eaten before? }\end{array}$} & Baseline, mean (SD) & $5.75(3.32)$ & $5.88(3.14)$ & $0.01(0.53)$ \\
\hline & Adjusted Changet, mean (SE) & $0.51(0.37)$ & $0.50(0.38)$ & $P=0.99$ \\
\hline \multirow{2}{*}{$\begin{array}{l}\text { 8. How easy or hard would it be for you to prepare and cook } \\
\text { new recipes? }\end{array}$} & Baseline, mean (SD) & $7.24(3.03)$ & $6.70(2.97)$ & $0.39(0.47)$ \\
\hline & Adjusted Changet, mean (SE) & $0.86(0.33)$ & $0.46(0.34)$ & $p=0.40$ \\
\hline \multirow[t]{2}{*}{ Self-efficacy Sum } & Baseline, mean (SD) & $55.03(16.5)$ & $55.17(14.2)$ & $4.09(2.45)$ \\
\hline & Adjusted Changet, mean (SE) & $6.40(1.76)$ & $2.30(1.73)$ & $p=0.10$ \\
\hline
\end{tabular}

† Adjusted analyses control for site, baseline self-efficacy and education; *Statistically significant $(p<0.05)$

For self-efficacy sum $N=148$ (intervention $=64$ and control $=64$ ); For intervention group: $n=73$ for item $1, n=74$ for items 2,6 and $8, n=70$ for items 3 and $4, n=71$ for items 5 and 7; For control group: $\mathrm{n}=68$ for items 1, 3, 4 and 5, $n=67$ for items 2, 5,7 and 8

SD standard deviation, SE Standard error

mobile market approach that we did not measure directly such as community engagement or the "share" model. Based on qualitative feedback from focus groups with customers (unpublished data), we hypothesize that purchasing a share of produce each week led to more purchasing and consumption than would be seen with a traditional market model of selecting individual produce items. For our model, customers had the option of buying individual pieces of produce or shares. While data indicate that those who ever purchased a share had greater $F \& V$ intake at follow-up, purchasing data was not complete enough to look at dose-response. Further research is needed to understand whether sales of shares is associated with greater consumption than would be seen with a traditional market model.

\section{Limitations}

In order to maintain partner engagement, we ended recruitment at most sites before we reached our study goals [19]. Consequently our baseline numbers $(N=201)$ were lower than the anticipated 300. Extended timelines may also have affected drop-out, which was higher than our pilot work (71\% actual retention rate vs. $80 \%$ anticipated retention rate) [19]. While the research team and the VV staff worked closely together on major decisions that would affect the research, VV staff was ultimately responsible for implementation. Therefore, VV prices, nutrition education programming, and intervention duration were not always consistent across sites. Recruitment and implementation challenges are common in communitybased research, especially with minority populations, [33] and the randomized controlled design provides adequate experimental control despite these threats to internal validity.

Another limitation is that this study relied on a food frequency questionnaire (FFQ) to collect diet information. While FFQs are acceptable and have been used in other mobile market research [13,34], they only reflect limited number of vegetable categories and may not have adequately captured some of the local produce that was commonly available in North Carolina (leafy greens, root vegetables, etc.). As with all self-report dietary assessment measures, results are susceptible to bias. To help improve the accuracy of FFQs, we provided portion size sheets to help participants with their answers, but only about a fifth of participants reported using them when completing the surveys.

As noted above, much of the difference in F\&V consumption we saw between the intervention and control groups was due to decreases in the control group. While 
we don't know the cause of these decreases, we saw a similar trend in our pilot work which could represent a regression to the mean. We also reviewed the data for a possible effect of seasonality on F\&V intake across months and seasons at each time point, but did not find any patterns that suggested a seasonality bias. Future work should consider using 24-h recalls or adapting standard FFQs to account for local or regional produce.

Despite its limitations, these methods represent an improvement to previous mobile market research. Although the study did not reach goal participation numbers, these projections were based on studies that were similar, but that ultimately had different ICCs and standard deviations than the present study. Our estimates also anticipated a smaller (more conservative) difference in the change in F\&V intake between intervention and control participants than we saw with our main adjusted analysis so we could more easily detect a significant difference. When extremes removed, the difference was smaller than the anticipated change (0.5/cup vs. a projected 0.75 cups/day difference) which could explain why that comparison did not reach statistical significance.

\section{Public health implications}

Mobile markets are a promising strategy for improving $F \& V$ consumption in lower-income and low food access communities; they have low overhead and start-up costs so they overcome many of the challenges associated with building new food retail. As their sales can be limited to fresh produce and other healthy items, they do not have the same challenges faced by interventions in existing food retail stores, which generally are able to promote healthy items, but are limited in their ability to decrease exposure to unhealthy items. Furthermore, our team designed VV to meet the needs of underserved and lower-income communities in North Carolina. Extensive formative research indicated that mobile markets were needed and wanted in the target communities and were preferred above several possible other strategies [35, 36]. Not only were we able to demonstrate an impact of VV on F\&V intake, but the majority of customers also selfreported reported several other benefits to their health and diet.

While VV was able to improve F\&V consumption among customers, challenges still exist to implementing this program on a larger scale. First, financial viability is a concern, as many of mobile markets described in the published literature have closed due to issues with the sustainability of the model. VV experimented with a sliding scale model, but found it difficult to sell enough produce on the higher end of the scale to support the reduced cost purchases. Another strategy included reducing waste through preordering of produce, but this can be difficult to manage without sophisticated point-of-sale software. Markets may have success leveraging local programs such as "Double Up Food Bucks" which allow SNAP participants to increase their buying power [37], but need to consider that many lower-income individuals are not eligible for SNAP and may still benefit from reduced cost produce. Future research should aim to better understand approaches for financial sustainability, including looking at creative partnerships with for-profit businesses or cost-offset models.

Mobile market programs also need to consider how to best improve their reach. More focus is needed on community engagement and customer relations as potential mobile market shoppers often have concerns about the quality and affordability of the F\&V and the trustworthiness of mobile market providers [36, 38, 39]. The current study sought to improve trust by involving community organizations as liaisons to the VV, however their community outreach capabilities were also limited. Future programs should consider creating community advisory committees or hiring residents as mobile market staff.

\section{Conclusions}

This was the first study to demonstrate using a randomized controlled trial design that mobile produce markets can be an effective means for increasing F\&V consumption among lower-income customers. If the recommended improvements to financial models and community engagement can be achieved, VV has the potential to become an effective, scalable intervention for improving F\&V consumption in lower-income communities.

\section{Additional file}

Additional file 1: Recruitment and Retention Rates for 12 Community Sites Participating in Veggie Van Study. (DOCX 13 kb)

\section{Abbreviations}

ANCOVA: Analysis of covariance; CSA: Community supported agriculture; EBT: Electronic benefit transfer; F\&V: Fruits and vegetables; FFQ: Food frequency questionnaire; GLMM: Generalized linear mixed model; ICC: Intraclass correlation; SNAP: Supplemental nutrition assistance program; W: Veggie van

\section{Acknowledgements}

We would like to thank all of the Veggie Van customers and study participants who helped us to design and evaluate this program. Our research would also not have been possible without the hard work of the Veggie Van team, including Jillian Mickens, Casey Horowitz and Kate Wagner, and all of the community organizations and partners that hosted Veggie Van.

\section{Funding}

The evaluation was funded by the National Cancer Institute (1R21CA173042). In addition, Dr. Leone's effort was supported by the Cancer Health Disparities Training Program (1T32CA128582) and the 3E program on Built Environment, Health Behavior, and Health Outcomes at the University at Buffalo. Dr. Haynes-Maslow's effort was supported by Health Care Quality and Patient Outcomes Pre-doctoral Fellowship (2T32NR008856). The Veggie Van program was funded by the Blue Cross and Blue Shield Foundation of North Carolina 
and the United States Department of Agriculture's Local Food

Promotion Program.

\section{Availability of data and materials}

The datasets used and/or analyzed during the current study available from the corresponding author on reasonable request.

\section{Authors' contributions}

$\mathrm{LL}$ and AA conceived and supervised the study; All authors were involved in oversight of recruitment and data collection; GT, GZ and LL completed the analyses. LL and GT drafted the manuscript. All authors read and approved the final manuscript.

\section{Ethics approval and consent to participate}

This study was approved by the Institutional Review Board at the University of North Carolina at Chapel Hill. All participants in this study provided verbal informed consent.

\section{Consent for publication}

Not applicable.

\section{Competing interests}

Drs. Leone. Haynes-Maslow and Armstrong-Brown are unpaid board members for Community Nutrition Partnership, the non-profit organization that runs the Veggie Van program.

\section{Publisher's Note}

Springer Nature remains neutral with regard to jurisdictional claims in published maps and institutional affiliations.

\section{Author details}

Department of Community Health and Health Behavior, University at Buffalo, Buffalo, NY, USA. ${ }^{2}$ Center for Health Promotion and Disease Prevention, University of North Carolina at Chapel Hill, Chapel Hill, NC, USA. ${ }^{3}$ Department of Agricultural and Human Sciences, North Carolina State University, Raleigh, NC, USA. ${ }^{4}$ RTI International, Research Triangle Park, NC, USA.

Received: 28 July 2017 Accepted: 18 December 2017 Published online: 05 January 2018

\section{References}

1. Dankwa-Mullan I, Rhee KB, Williams K, Sanchez I, Sy FS, Stinson N Jr, Ruffin J. The science of eliminating health disparities: summary and analysis of the NIH summit recommendations. Am J Public Health. 2010:100(Suppl 1):S12-8.

2. Whitney EN. Understanding nutrition. Toronto: Nelson Education; 2012.

3. Leone LA, Beth D, Ickes S, MacGuire K, Nelson E, Smith RA, Tate DF, Ammerman AS. Attitudes towards fruit and vegetable consumption and farmers' market usage among low-income north Carolinians. J Hunger Environ Nutr. 2012;7:64-76

4. Haynes-Maslow L, Parsons SE, Wheeler SB, Leone LA. A qualitative study of perceived barriers to fruit and vegetable consumption among low-income populations, North Carolina, 2011. Prev Chronic Dis. 2013;10:E34

5. Walker RE, Keane CR, Burke JG. Disparities and access to healthy food in the United States: a review of food deserts literature. Health Place. 2010;16:876-84.

6. Story M, Kaphingst KM, Robinson-O'Brien R, Glanz K. Creating healthy food and eating environments: policy and environmental approaches. Annu Rev Public Health. 2008;29:253-72.

7. What is the Healthy Food Financing Initiative? Healthy Food Financing Initiative, Office of Community Services; 2017. www.acf.hhs.gov/ocs/ programs/community-economic-development/healthy-food-financing.

8. Sadler RC, Gilliland JA, Arku G. A food retail-based intervention on food security and consumption. Int J Environ Res Public Health. 2013;10:3325-46.

9. Dubowitz T, Ghosh-Dastidar M, Cohen DA, Beckman R, Steiner ED, Hunter GP, Florez KR, Huang C, Vaughan CA, Sloan JC, et al. Diet and perceptions change with supermarket introduction in a Food Desert, but not because of supermarket use. Health Aff (Millwood). 2015:34:1858-68.

10. Cummins S, Flint E, Matthews SA. New neighborhood grocery store increased awareness of food access but did not alter dietary habits or obesity. Health Aff (Millwood). 2014;33:283-91.
11. Gorham G, Dulin-Keita A, Risica PM, Mello J, Papandonatos G, Nunn A, Gorham S, Roberson M, Gans KM. Effectiveness of fresh to you, a discount fresh fruit and vegetable market in low-income neighborhoods, on Children's fruit and vegetable consumption, Rhode Island, 2010-2011. Prev Chronic Dis. 2015;12:E176.

12. Freedman DA, Choi SK, Hurley T, Anadu E, Hebert JR. A farmers' market at a federally qualified health center improves fruit and vegetable intake among low-income diabetics. Prev Med. 2013;56:288-92.

13. Evans AE, Jennings R, Smiley AW, Medina JL, Sharma SV, Rutledge R, Stigler MH, Hoelscher DM. Introduction of farm stands in low-income communities increases fruit and vegetable among community residents. Health Place. 2012;18:1137-43.

14. Abusabha R, Namjoshi D, Klein A. Increasing access and affordability of produce improves perceived consumption of vegetables in low-income seniors. J Am Diet Assoc. 2011;111:1549-55.

15. Leone LA, Haynes-Maslow L, Ammerman AS. Veggie van pilot study: impact of a mobile produce market for underserved communities on fruit and vegetable access and intake. J Hunger Environ Nutr. 2017;12:89-100.

16. Quandt SA, Dupuis J, Fish C, D'Agostino RB Jr. Feasibility of using a community-supported agriculture program to improve fruit and vegetable inventories and consumption in an underresourced urban community. Prev Chronic Dis. 2013;10:E136.

17. Robinson T. Applying the socio-ecological model to improving fruit and vegetable intake among low-income African Americans. J Community Health. 2008:33:395-406

18. Caspi CE, Sorensen G, Subramanian SV, Kawachi I. The local food environment and diet: a systematic review. Health Place. 2012;18:1172-87.

19. Tripicchio GL, Grady Smith J, Armstrong-Brown J, McGuirt J, Haynes-Maslow L, Mardovich S, Ammerman AS, Leone L. Recruiting Community Partners for Veggie van: strategies and lessons learned from a mobile market intervention in North Carolina, 2012-2015. Prev Chronic Dis. 2017:14:E36.

20. Leone LA, Tripicchio GL, Haynes-Maslow L, McGuirt J, Grady Smith JS, Armstrong-Brown J, Kowitt S, Gizlice Z, Ammerman AS. A clusterrandomized trial of a mobile produce market program in 12 communities in North Carolina: program development, methods and baseline results. J Acad Nutr Diet Under Rev.

21. Thompson FE, Midthune D, Kahle L, Dodd KW. Development and Evaluation of the National Cancer Institute's Dietary Screener Questionnaire Scoring Algorithms. J Nutr. 2017;147(6):1226-33.

22. Thompson FE, Subar AF, Smith AF, Midthune D, Radimer KL, Kahle LL, Kipnis $\checkmark$. Fruit and vegetable assessment: performance of 2 new short instruments and a food frequency questionnaire. J Am Diet Assoc. 2002;2002:1764-72.

23. Yaroch AL, Tooze J, Thompson FE, Blanck HM, Thompson OM, Colón-Ramos U, Shaikh AR, McNutt S, Nebeling LC. Evaluation of Three Short Dietary Instruments to Assess Fruit and Vegetable Intake: The National Cancer Institute's Food Attitudes and Behaviors Survey. Journal of the Academy of Nutrition and Dietetics. 2012;112:1570-7.

24. Dietary Screener Questionnaires (DSQ) in the NHANES 2009-10. National Cancer Institute; 2016. https://epi.grants.cancer.gov/nhanes/dietscreen/ questionnaires.html.

25. Echeverria SE, Diez-Roux AV, Link BG. Reliability of self-reported neighborhood characteristics. J Urban Health. 2004:81:682-701.

26. Green SH, Glanz K. Development of the perceived nutrition environment measures survey. Am J Prev Med. 2015:49:50-61.

27. Anderson ES, Winett RA, Wojcik JR. Social-cognitive determinants of nutrition behavior among supermarket food shoppers: a structural equation analysis. Health Psychol. 2000;19:479-86

28. Donner A, Klar N. Statistical considerations in the design and analysis of community intervention trials. J Clin Epidemiol. 1996;49:435.

29. Donner A, Klar N. Design and analysis of cluster randomization trials in Health Research. New York: Oxford University Press; 2000.

30. Leone LA, Allicock M, Pignone MP, Walsh J, Johnson LS, Armstrong-Brown J, Carr C, Landford A, Ni A, Resnicow K, Campbell MK. Cluster Randomized Trial of a Church-based Peer Counselor and Tailored Newsletter Intervention to Promote Colorectal Cancer Screening and Physical Activity among Older African Americans. Health Educ Behav. 2016;43(5):568-76.

31. Frison L, Pocock S. Repeated measures in clinical trials: analysis using mean summary statistics and its implications for design. Stat Med. 1992;11:1685-704.

32. Vickers AJ, Altman DG. Statistics notes: analysing controlled trials with baseline and follow up measurements. BMJ. 2001;323:1123.

33. Ibrahim S, Sidani S. Strategies to recruit minority persons: a systematic review. J Immigr Minor Health. 2014;16:882-8. 
34. Gans KM, Gorham G, Risica PM, Dulin-Keita A, Dionne L, Gao T, Peters S, Principato L. A multi-level intervention in subsidized housing sites to increase fruit and vegetable access and intake: rationale, design and methods of the 'Live well, viva Bien' cluster randomized trial. BMC Public Health. 2016;16:521.

35. Haynes-Maslow L, Parsons S, Leone L. Real \& perceived food deserts in Orange \& Durham County. North Carolina: Southern Food and Ve; 2011.

36. Haynes-Maslow L, Auvergne L, Mark B, Ammerman A, Weiner BJ. Lowincome Individuals' perceptions about fruit and vegetable access programs: a qualitative study. J Nutr Educ Behav. 2015;47:317-24. e311

37. Cohen AJ, Richardson CR, Heisler M, Sen A, Murphy EC, Hesterman OB, Davis MM, Zick SM. Increasing use of a healthy food incentive: a waiting room intervention among low-income patients. Am J Prev Med. 2017:52:154-62.

38. Zepeda L, Reznickova A, Lohr L. Overcoming challenges to effectiveness of mobile markets in US food deserts. Appetite. 2014;79:58-67.

39. McGuirt JT, Ward R, Elliott NM, Bullock SL, Jilcott Pitts SB. Factors influencing local food procurement among women of reproductive age in rural eastern and western North Carolina, USA. J Agric Food Syst Community Dev. 2014;4:143-54.

Submit your next manuscript to BioMed Central and we will help you at every step:

- We accept pre-submission inquiries

- Our selector tool helps you to find the most relevant journal

- We provide round the clock customer support

- Convenient online submission

- Thorough peer review

- Inclusion in PubMed and all major indexing services

- Maximum visibility for your research

Submit your manuscript at www.biomedcentral.com/submit
Biomed Central 